\title{
A Study of Techniques for Facial Detection and Expression Classification
}

\author{
G.Hemalatha ${ }^{1}$, C.P. Sumathi ${ }^{2}$ \\ ${ }^{1}$ Research Scholar, Manonmaniam Sundaranar University, Tirunelveli, India \\ ${ }^{2}$ Department of Computer Science, SDNB Vaishnav College For Women, Chennai, \\ India
}

\begin{abstract}
Automatic recognition of facial expressions is an important component for human-machine interfaces. It has lot of attraction in research area since 1990's.Although humans recognize face without effort or delay, recognition by a machine is still a challenge. Some of its challenges are highly dynamic in their orientation, lightening, scale, facial expression and occlusion. Applications are in the fields like user authentication, person identification, video surveillance, information security, data privacy etc. The various approaches for facial recognition are categorized into two namely holistic based facial recognition and feature based facial recognition. Holistic based treat the image data as one entity without isolating different region in the face where as feature based methods identify certain points on the face such as eyes, nose and mouth etc. In this paper, facial expression recognition is analyzed with various methods of facial detection, facial feature extraction and classification.
\end{abstract}

\section{KEYWORDS}

Face detection,, Feature extraction, Machine learning, Classification, Expression recognition.

\section{INTRODUCTION}

Emotion is a state of feeling like thoughts, psychological changes and expressions. Emotions positively affects intelligent functions such as decision making, perception and empathic understanding according to Beeahara et.al's[1].The approach on Facial Action Coding System (FACS) which separates the expression into upper and lower face action. FACS was developed by EKMAN [2] for facial expression description. Facial expression recognition involves three steps face detection, feature extraction and expression classification.

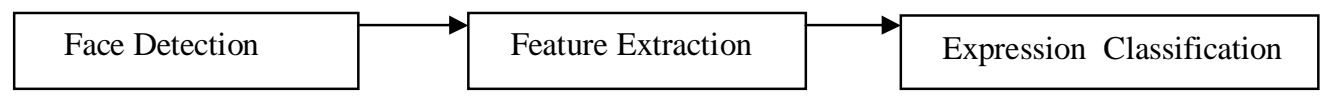

Figure1. Steps involved in Facial Detection and Expression Classification

\section{FACE DETECTION}

The first step in face detection is preprocessing. The reason is to obtain pure facial images with normalized intensity, uniform size and shape. The steps involved in converting a image to a normalized pure facial image for feature extraction is detecting feature points, rotating to line up,

DOI : 10.5121/ijcses.2014.5203 
International Journal of Computer Science \& Engineering Survey (IJCSES) Vol.5, No.2, April 2014

locating and cropping the face region using a rectangle, according to the face model. Detecting faces in a single image involves four methods Knowledge based, Facial invariant, Template matching and Appearance based according to the author Ming-Hsuan yang et.al's [3] is referred in the below table1.

Table 1. Facial Detection methods and its related works:

\begin{tabular}{|c|c|}
\hline Methods & Related Works \\
\hline Knowledge based & Multi resolution rule based method \\
\hline $\begin{array}{l}\text { Feature invariant } \\
\text { Facial features } \\
\text { Texture } \\
\text { Skin color } \\
\text { Multiple Feature }\end{array}$ & $\begin{array}{l}\text { Grouping of edges } \\
\text { Space gray-level Dependence matrix (SGLD) of face } \\
\text { pattern } \\
\text { Mixture of Gaussian } \\
\text { Integration of skin color, shape and size }\end{array}$ \\
\hline $\begin{array}{l}\text { Template Matching } \\
\text { Predefined face templates } \\
\text { Deformable templates }\end{array}$ & $\begin{array}{l}\text { Shape template } \\
\text { Active shape model(ASM) }\end{array}$ \\
\hline $\begin{array}{l}\text { Appearance Based } \\
\text { Eigenface } \\
\text { Distribution based } \\
\text { Neural Network } \\
\text { Support } \\
\text { Machine(SVM) Vector } \\
\text { Naive Bayes classifier } \\
\text { Hidden markov } \\
\text { Model(HMM) } \\
\text { Information-Theoretical } \\
\text { approach }\end{array}$ & $\begin{array}{l}\text { Eigenvector decomposition and clustering } \\
\text { Gaussian distribution and multilayer perception } \\
\text { Ensemble of neural networks and arbitration } \\
\text { SVM with polynomial kernel } \\
\text { Joint statistics of local appearance and position } \\
\text { Higher order statistics with HMM } \\
\text { Kullback relative information }\end{array}$ \\
\hline
\end{tabular}

\subsection{Related work for Detecting Regions in the Face}

According to the author Rajesh AP et.al's [4] illumination effect is eliminated for scaling the image to fixed size. To detect facial feature points automatically, the face has to be located in the image. For face detection, the scheme proposed by WolfKienzle [5] is commonly used with the technique of Viola-Jones [6] algorithm. In this paper the face detection algorithm detects the face as shown in Figure 2(a). Face is enclosed by a rectangle. The algorithm gives the coordinates of upper left corner of rectangle and gives the width and height of the rectangle as in Figure 2(b).
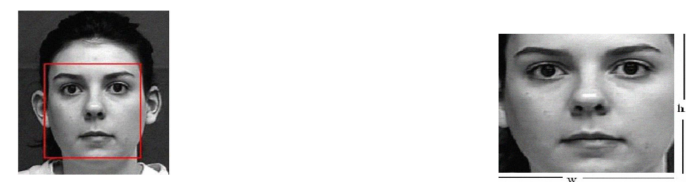

Figure2. (a)Face Detection.

(b) Cropped Face Image.

Binary image is scanned vertically to get first and last black point, with corners of eyes then starts from eyebrows left side of left eye and right side of right eye is cropped. Here image 
normalization is applied for thresholding and vertical scanning technique to get each eyebrow coners. Again the same techniques are applied to detect nostrils and the mouth region, here also the image is cropped from left as well as from right side, then image normalization, thresholding, and vertical scanning techniques are applied to detect lip corners. The algorithm has been tested on Cohn-Kanade database as well as on Informatics and Mathematical Modeling (IMM) [7] database. The detection of 14 facial feature points with average accuracy of $86 \%$ on CohnKanade database and $83 \%$ on IMM face database.

\subsection{Review for detection methods:}

\subsubsection{Knowledge Based:}

According to Yu-Buhee et.al's [8] knowledge on human face such as skin color and shape is directly set to window size and color signature for computing the color distance. The method has reached a detection of $93.4 \%$ with false positive as $7.1 \%$.

\subsubsection{Feature Based:}

According to Kin Choong Yow et.al's [9] the algorithm detects the feature points from the image using spatial filtering techniques and then groups the points into face candidates using perceptual grouping principles and selects the true candidate using probabilistic frame work. This method has the detection rate as $85 \%$ with 110 images with different scale orientation and view point.

\subsubsection{Texture Based:}

According to A.Punitha et.al's [10] the emotion recognition is based on the texture feature extracted from the gray-level co-occurance matrix (GLCM), the extracted GLCM features are trained with Support Vector Machine with different kernels. The images in the database are of pixels $63 * 63$ and GLPM is computed for all the images. The second order statistical texture features are extracted from the GLPM is given as input to the SVM for classification. The detection rate is $90 \%$.

\subsubsection{Skin color Based:}

According to Sanjay Kr.Singh et.al's [11] three color spaces RGB, YCbCr and HSI are used to compare algorithms. These colors are combined to get a new skin color based on face detection algorithm.After getting skin region, facial features eyes and mouth are extracted by darkening the background colors and then the image is transformed to gray scale and binary image by suitable threshold. The detection rate is $95.18 \%$ of accuracy.

\subsubsection{Multiple Features:}

According to Jiaming Li et.al's [12] multiple face region features are selected by Adaboost algorithm. Face is divided into sub regions by Adaboost based on multiple region Orthogonal component principle component analysis features like eyes, mouth and nose. The region combination were used as input to AdaBoost classifier, this at each stage chooses the best such combination before changing the weights for next iteration. The detecting performance in multiple feature is much better compared to general Orthogonal component principle component analysis method. 
International Journal of Computer Science \& Engineering Survey (IJCSES) Vol.5, No.2, April 2014

\subsubsection{Template Matching:}

According to Caifeng Shan et.al's [13] face is represented based on statistical local features, local binary patterns(LBP) for person independent expression recognition.LBP is used for texture analysis along with Support Vector Machine for low resolution and better performance.LBP labels pixels of each image by thresholding $3 * 3$ with neighborhood along with center value of each pixel. By considering the result as binary number finally 256 bin histogram of LBP labels computed over a region is used as texture descriptor, the number codify curved edges, spots and flat areas as microtexton. The recognition with MMI is $86.97 \%$ and $85.6 \%$ on JAFFE database.

\subsubsection{Active Shape Model:}

According to Rajesh A,Patil et.al's [14] the expression in image sequence is done with candid wire frame model and active appearance algorithm for tracking and Support Vector Machine(SVM) for classification is used. The geometric displacement of wire frame nodes is defined as difference of the node coordinates between and greatest intensity frame which is given as an input to SVM for facial expression recognition. When expressions are changed in subsequent frames the model deform its shape till the last frame.

\subsubsection{Appearence Based:}

According to Yogesh Tayal et.al's[15] eigenface based algorithm is applied to variety of images taken under different lighting and backgrounds, the size of an image is 180*200 and time taken by the algorithm is 4.5456 seconds. Here weight and Euclidean distance of an input image is taken for computing the features and then face is compared with database for recognition.

\subsubsection{Distribution Features:}

According to Jeemoni Kalita et.al's[16] the images were acquired and five significant portions are cropped from the image which is perfomed for extraction and thus store eigen vectors specific to the expressions. Eigen vectors are computed and input facial image is recognized when similarity was obtained, the Euclidean distance between the test image and different expression is calculated. The classification is done with Support Vector Machine. The recognition for JAFFE database is $92.93 \%$ and Cohn-Kanade is $94.8 \%$.

\section{FEATURE EXTRACTION}

Feature extraction is a method in facial recognition. It involves several steps like dimensionality reduction, feature extraction and feature selection. Dimensionality reduction is an important task in pattern recognition system.

\subsection{Feature Extraction using Discrete Cosine Transform (DCT):}

According to SandeepK.Gupta et.al's[17] Discrete Cosine Transform (DCT) is applied on input image(img).The DCT coefficient are kept in Zigzag positions and these are implemented to convert 2D DCT image matrix to feature vector, here domain frequency component is kept at the start vector.The features like eyes and mouth is extracted from input image and, DCT is applied on this sub image to get DCT coefficient of eyes and mouth region, finally these features are added with feature vector.AdaBoost is used as a classifier for emotion recognition.The recognition rate is $75.94 \%$. 
International Journal of Computer Science \& Engineering Survey (IJCSES) Vol.5, No.2, April 2014

\subsection{Facial Feature Extraction using Gabor Filter:}

According to Ziyang Zhang et.al's [18] the facial images are preprocessed based on affine transform to normalize the faces, the evaluation is done with separability of different Gabor filters, these filters are used to separate different expression. Dimension reduction achieved by Principle Component Analysis(PCA) and Feasibility of Linear Discriminant Analysis(FLDA) multiclassifier are used for recognition. The classifier assumes the discriminate function to be a linear function of the feature data. In this case the data is the feature vector obtained. According to the author the Gabor filter selection reduce the dimension of feature space and computation complexity. The expression database used here to examine recognition system is the JAFFE database and the recognition rate is $93 \%$ and above.

\subsection{Facial Feature Extraction using Principle Component Analysis:}

According to the author Zhiguo Niu et.al's [19] Weighted Principal Component Analysis(WPCA) method is used on multi feature fusion. This high dimensional local self related features are extracted from facial expression images, thus the images are divided into regions. Then WPCA is used for dimension reduction, the weights is quickly determined based on facial action coding system, also Radial Basis Function(RBF) is used.Support Vector Machine algorithm is applied for classification of facial expression characteristics. Finally Euclidean distance is calculated to obtain the similarity between templates and then facial expression recognition is done with nearest algorithm. The recognition rate is $88.25 \%$ in this method.

\subsection{Facial Feature Extraction using Independent Component Analysis:}

According to the author Marian Stewart Bartlett et.al's [20] Independent Component Analysis(ICA) derived from the principle of optimal information transfer through signodial neurons. ICA is used to perform on face images in the FERET database under two different architecture. The first architecture takes images as random variables and pixels as random trials, hence ICA consider images statistically independent images these images are sparse and localized in space resembling facial features.The second architecture takes pixels as random variables and images as random trials, here image coefficient are approximately independent and thus give result in factorial face code. Finally the two ICA representation are combined in single classifier. In this paper sources was controlled by dimension reduction through Principal Component Analysis and information maximization algorithm is used for performance of ICA.The overall classification performance is $99.8 \%$ with 400 out of 500 test images.

\subsection{Facial Feature Extraction using Linear Discriminant Analysis}

According to the author Li Fen Chen et.al's [21] in this paper more efficient, accurate and stable method is proposed to calculate the discriminant vectors based on Fisher's criterion and here a two stage procedure is implemented. In the first stage the homogeneous regions of a face image are grouped as same partition based on geometric characteristics, then the mean gray value is used for pixels within the partition region and thus the face image is reduced as feature vector.In the second stage the feature vector is used to determine discriminant projection axes based on the proposed LDA. The vectors are clustered using K-means clustering method with each changed samples. The performance in the proposed method is $91 \%$. 
International Journal of Computer Science \& Engineering Survey (IJCSES) Vol.5, No.2, April 2014

\section{CLASSIFICATIONS}

\subsection{Hidden Markov Model (HMM) as classifier:}

According to the author Teik-Toe-TEOH et.al's [22] in this paper Hidden markov model is developed to classify the higher level emotions states like interested, unsure, disagreeing, encouraging and discouraging from the lower level emotions like neutral ,joy, surprise and sad. An emotional indexing is modeled is used to understand the states of emotions thus it functions as database hence there is an one to one mapping is done between an facial emotions and expressions. The indexer receives the symbol and matches them against stored in the mind and then chooses symbols to represent concepts in the index. Hidden markov expert rule(HMER) is used for segmentation and to recognize emotional states from a set of video sequences. A classification framework is used for every incoming video frame and hence the facial expression recognizer identifies the head and actions which combines to form displays and thus HMER represents dynamic display and classification framework. HMER topology is constructed for four state emotional state like $\mathrm{N}$ represents neutral state and SU for surprise etc from which it is possible to transit the higher level emotion states. Here the probabilistic framework for modeling ,time varying sequences and convergence of recognition computation runs in real time. The performance of recognizing the emotions unsure is $87 \%$ and disagreeing $78 \%$.

\subsection{Neural Networks as classifier:}

According to the author Er.MonicaVerma et.al's [23] in this paper there is a combination of two methods Feature extraction and Neural network and two stages are involved for face detection and classification. Images are preprocessed in order to decrease the time and to increase the quality of image. In the first stage features are extracted from face image using Gabor filters with orientation of $5 * 8$ that is 40 filters. Second stage to classify the facial images obtained from feature vector using Neural network. Here the Neural network is trained with face and non-face images from Yale face database. The images in the dataset is of $27 * 18$ pixels, the images are in the gray scale in TIFF format. The performance rate is $84.4 \%$.

\subsection{Support Vector Machine as classifier:}

According to author Stewart Bartlett et.al's [24] each video frame is first scanned in real-tine to detect frontal faces, then the faces are scaled into image patches of equal size along with a bank of Gabor energy filters. The filtered image is given as an input to recognition classifier which codes expression into different dimensions. The facial features are selected from gabor filters using AdaBoost and this again trained with Support Vector Machine. The author developed endto-end system that provides different facial expression codes at 24 frames per second and animates a computer generated characteristics, fully automated facial action coding is also applied and recognition rate is $93 \%$.

\subsection{AdaBoost as classifier:}

According to the author Chin-Shyurng Fahn et.al's[25] the frontal face in an image sequence is classified into seven classes like an neutral, joy, sad, surprise, anger, fear, disgust. Here the recognition system is done without characteristic blocks. In this paper skin color detection techniques is used for face detection that is $\mathrm{YCbCr}, \mathrm{HSI}, \mathrm{RGB}$ is applied for the images. Then the skin color region is distinguished from non skin color region by means of lower and upper bound threshold hence the value are taken between 3 and 38 as the range of skin colors. Then the facial feature detections is done using Color Space Transformation, Connected Component Labeling 
Technique, Face Region Verification like face segmentation, Pupils detection like referring height and width of the face region etc. Thus the landmarks regions like eyes, eyebrows , mouth of the facial features are extracted and finally the facial expressions is distinguished by the displacement of land mark features in the face by the algorithm proposed by the author using AdaBoost based classifier. Hence the accuracy rate is $90 \%$.

Table 2. Listing the various Methods for Facial Feature Extraction and Classification

\begin{tabular}{|c|c|c|c|c|}
\hline S.No & Author & Title & Journal & Method \\
\hline 1. & $\begin{array}{l}\text { Hiroshi } \\
\text { Kobayashi et.al's } \\
\text { [26] }\end{array}$ & $\begin{array}{l}\text { Analysis of Neural } \\
\text { Network } \\
\text { Recognition } \\
\text { characteristics at } 6 \\
\text { Basic Facial } \\
\text { Expression }\end{array}$ & $\begin{array}{l}\text { IEEE } \\
\text { International } \\
\text { Workshop on } \\
\text { Robot and } \\
\text { Human } \\
\text { Communicatio } \\
\text { n 0-7803- } \\
\text { 2002-6/94, } \\
\text { 1994 IEEE }\end{array}$ & $\begin{array}{l}\text { Action Unit is used for } \\
\text { describing basic } \\
\text { muscle movement of } \\
\text { human face with } \\
\text { Neural Network as } \\
\text { Classifier }\end{array}$ \\
\hline 2. & $\begin{array}{l}\text { Chung-Lin Huang } \\
\text { et.al's [27] }\end{array}$ & $\begin{array}{l}\text { Facial Expression } \\
\text { Recognition Using } \\
\text { Model-Based } \\
\text { Feature Extraction }\end{array}$ & $\begin{array}{l}\text { Vol. 8, No. 3, } \\
\text { September, pp. } \\
\text { 278-290, } 1997\end{array}$ & $\begin{array}{l}\text { Point Distribution } \\
\text { Model and Gray Level } \\
\text { Model to find Facial } \\
\text { features with } 10 \text { action } \\
\text { points and finally } \\
\text { calculates the } \\
\text { recognition. }\end{array}$ \\
\hline 3. & $\begin{array}{l}\text { Beat Fase IDIAP } \\
\text { et.al's [28] }\end{array}$ & $\begin{array}{l}\text { Head Pose invariant } \\
\text { Facial Expression } \\
\text { Recognition using } \\
\text { Convolutional } \\
\text { Neural Network }\end{array}$ & $\begin{array}{l}\text { Fourth IEEE } \\
\text { Internal } \\
\text { conference on } \\
\text { Multimodel } \\
\text { interfaces } \\
0-7695-1834- \\
6 / 02 \text { @ } 2002 \\
\text { IEEE }\end{array}$ & $\begin{array}{l}\text { Convolution Neural } \\
\text { Network (CNN) with } \\
\text { Multiscale feature } \\
\text { extractors compared } \\
\text { with Multi layer } \\
\text { perception }\end{array}$ \\
\hline 4. & Khalid et.al's [29] & $\begin{array}{l}\text { Face Expression } \\
\text { Recognition with } \\
\text { Relevance Vector } \\
\text { Machine }\end{array}$ & $\begin{array}{l}\text { ICME (Multi } \\
\text { media \& } \\
\text { Expo) IEEE } \\
\text { International } \\
\text { Conference } \\
\text { Pg 193-196 } \\
\text { 24th Oct 2005 }\end{array}$ & $\begin{array}{l}\text { Relevance Vector } \\
\text { Machine (RVM ) is } \\
\text { used as classification } \\
\text { techniques in static } \\
\text { images Cohn Kanade } \\
\text { database }\end{array}$ \\
\hline 5. & $\begin{array}{l}\text { Aleksic P.S et.al's } \\
\text { [30] }\end{array}$ & $\begin{array}{l}\text { Automatic facial } \\
\text { expression } \\
\text { recognition using } \\
\text { facial animation } \\
\text { parameters and multi } \\
\text { stream Hidden } \\
\text { Markov models. }\end{array}$ & $\begin{array}{l}\text { Vol 1 Issue : } 1 \\
\text { Pg No: } 3-11 \\
\text { March 2006 } \\
\text { IEEE Signal } \\
\text { Processing } \\
\text { Society }\end{array}$ & $\begin{array}{l}\text { Facial Animation } \\
\text { Parameters is detected } \\
\text { (FAP) and multi stream } \\
\text { Hidden Markov } \\
\text { models is used as } \\
\text { classifier. }\end{array}$ \\
\hline 6. & $\begin{array}{l}\text { Pritpal Dang } \\
\text { et.al's [31] }\end{array}$ & $\begin{array}{l}\text { Facial Expression } \\
\text { Recognition Using a } \\
\text { Two Stage Neural } \\
\text { Network. }\end{array}$ & $\begin{array}{l}\text { I-4244-1282-- } \\
\text { X107 @ } 2007 \\
\text { IEEE July 27- } \\
29 \text { Althene - } \\
\text { Greece }\end{array}$ & $\begin{array}{l}\text { Neural Network is } \\
\text { used for expression } \\
\text { classification, and 1st } \\
\text { stage used for } \\
\text { dimension reduction }\end{array}$ \\
\hline
\end{tabular}


International Journal of Computer Science \& Engineering Survey (IJCSES) Vol.5, No.2, April 2014

\begin{tabular}{|c|c|c|c|c|}
\hline & & & & $\begin{array}{l}\text { and } 2 \text { nd stage used for } \\
\text { classifying expression. } \\
\text { Back propagation \& } \\
\text { radial basis function } \\
(\mathrm{RBF}) \text { is used for } \\
\text { expression } \\
\text { classification. }\end{array}$ \\
\hline 7. & $\begin{array}{l}\text { Govind U Kharat } \\
\text { et.al's [32] }\end{array}$ & $\begin{array}{l}\text { Emotion Recognition } \\
\text { from Facial } \\
\text { Expression Using } \\
\text { Neural Network. }\end{array}$ & $\begin{array}{l}1-4244-1543- \\
8 / 08 \text { C } 2008 \\
\text { IEEE }\end{array}$ & $\begin{array}{l}\text { Discrete cosine } \\
\text { transform, Multi layer } \\
\text { perception, Principal } \\
\text { component analysis \& } \\
\text { (GFFNN) generalized } \\
\text { Feed Forward Neural } \\
\text { Network for emotion } \\
\text { recognition is used } \\
\text { with MATLAB. }\end{array}$ \\
\hline 8. & $\begin{array}{l}\text { Kazmil S.B. } \\
\text { Qurat - ul - Ain } \\
\text { et.al's [33] }\end{array}$ & $\begin{array}{l}\text { Texture } \\
\text { based } \\
\text { expression } \\
\text { recognition } \\
\text { Baysing acial } \\
\text { Bang classifiers }\end{array}$ & $\begin{array}{l}\text { ICIET } 2010 \\
\text { Pg No } 1-69 \\
\text { Nov } 2010\end{array}$ & $\begin{array}{l}\text { Five parallel Bayesian } \\
\text { classifier each is } \\
\text { trained } \\
\text { to recognize a } \\
\text { particular facial } \\
\text { expression, } \\
\text { Multiclassification is } \\
\text { achieved by combining } \\
\text { multiple Bayesian } \\
\text { classifiers using } \\
\text { JAFFE database. }\end{array}$ \\
\hline 9. & $\begin{array}{l}\text { Jiequan Li } \\
\text { et.al's.[34] }\end{array}$ & $\begin{array}{l}\text { Automatic Face } \\
\text { emotion recognition } \\
\text { system }\end{array}$ & $\begin{array}{l}\text { Cybernet } \\
\text { Intelligent } \\
\text { Systems (CIS) } \\
2010 \text { IEEE 9th } \\
\text { International } \\
\text { Conference } \\
\text { Vol 1,Pg 1-6 }\end{array}$ & $\begin{array}{l}\text { Haar transform and } \\
\text { adaptive Adaboost } \\
\text { algorithm for face } \\
\text { identification and } \\
\text { Principal Component } \\
\text { Analysis (PCA) in } \\
\text { conjunction with } \\
\text { minimum distance } \\
\text { classifier for face } \\
\text { recognition. PCA \& } \\
\text { K- nearest Neighbor } \\
\text { (KNN) classification } \\
\text { algorithm and latter the } \\
\text { use of Negative matrix } \\
\text { factorization (NMF) \& } \\
\text { KNN algorithm tested } \\
\text { with Taiwanese \& } \\
\text { Indian face database } \\
\text { for facial recognition. }\end{array}$ \\
\hline
\end{tabular}


International Journal of Computer Science \& Engineering Survey (IJCSES) Vol.5, No.2, April 2014

\begin{tabular}{|c|c|c|c|c|}
\hline 10. & $\begin{array}{l}\text { Anissa Bouzalmat } \\
\text { et.al's [35] }\end{array}$ & $\begin{array}{l}\text { Face detection and } \\
\text { Recognition using } \\
\text { Back propagation } \\
\text { Neural Network and } \\
\text { Fourier Gabor Filters }\end{array}$ & $\begin{array}{l}\text { SIPIJ } \\
\text { Vol 2, No. } 3 \\
\text { Sep 2011 }\end{array}$ & $\begin{array}{l}\text { Feature vector based } \\
\text { on Fourier Gabor } \\
\text { filters are used as input } \\
\text { image to the Back } \\
\text { Propagation Neural } \\
\text { Network (BPMN) for } \\
\text { expression recognition. }\end{array}$ \\
\hline 11. & $\begin{array}{l}\text { Boughrara.H } \\
\text { et.al's [36] }\end{array}$ & $\begin{array}{l}\text { Face Recognition } \\
\text { under varying Facial } \\
\text { Expression based on } \\
\text { Perceived Facial } \\
\text { images and Local } \\
\text { Feature matching }\end{array}$ & $\begin{array}{l}2012 \\
\text { International } \\
\text { Conference on } \\
\text { Information } \\
\text { Technology } \\
\text { and e Services, } \\
\text { Pg 24-26 Mar } \\
2012\end{array}$ & $\begin{array}{l}\text { Perceived Facial } \\
\text { images is applied for } \\
\text { 2D recognition, and } \\
\text { Local feature matching } \\
\text { is used to calculate } \\
\text { probe face and gallery } \\
\text { ones and weighted sum } \\
\text { rule based fusion } \\
\text { scheme is tested with } \\
\text { the database. }\end{array}$ \\
\hline 12 . & $\begin{array}{l}\text { Rahulmathavan Y } \\
\text { et.al's [37] }\end{array}$ & $\begin{array}{l}\text { Facial Expression } \\
\text { Recognition in the } \\
\text { Encrypted Domain } \\
\text { Based on Local } \\
\text { Fisher Discriminant } \\
\text { Analysis }\end{array}$ & $\begin{array}{l}\text { Affective } \\
\text { Computing,IE } \\
\text { EE } \\
\text { Transcation on } \\
\text { vol 4,Issue } \\
\text { 1,Jan-Mar } \\
2013\end{array}$ & $\begin{array}{l}\text { Challenge of } \\
\text { performing facial } \\
\text { expression when the } \\
\text { test image is in } \\
\text { encrypted domain } \\
\text { without any decryption } \\
\text { using JAFFE and } \\
\text { MUG database. }\end{array}$ \\
\hline 13. & $\begin{array}{l}\text { Dileep M.R } \\
\text { et.al's[38] }\end{array}$ & $\begin{array}{l}\text { Lines of } \\
\text { Connectivity-Face } \\
\text { Model for } \\
\text { Recognition of the } \\
\text { Human Facial } \\
\text { Expressions. }\end{array}$ & $\begin{array}{l}\text { International } \\
\text { Journal of } \\
\text { Artificial } \\
\text { Intelligence } \\
\text { and } \\
\text { Mechatronics, } \\
\text { Vol 2,Issue } \\
\text { 2,ISSN 2320- } \\
\text { 5121, }\end{array}$ & $\begin{array}{l}\text { The faces are detected } \\
\text { by Triangular features } \\
\text { using Lines of } \\
\text { Connectivity }(\mathrm{LC}) \text { and } \\
\text { is a geometric } \\
\text { approach.The } \\
\text { recognition rate is } \\
93.8 \%\end{array}$ \\
\hline
\end{tabular}

\section{5. .CONCLUSION}

Although humans recognize facial expressions virtually without effort or delay, reliable expression recognition by machine is still a challenge, in achieving optimal preprocessing, feature extraction or selection, and classification, particularly under conditions of input data variability. To attain successful recognition performance, most current expression recognition approaches require some control over the imaging conditions because many real-world applications require operational flexibility. In particular, research into automatic expression recognition systems capable of adapting their knowledge periodically or continuously has not received much attention. The authors are of the opinion that robustness of expression recognition, against the variability of facial characteristics, would be difficult to achieve without incorporating adaptation in the recognition framework in future. 
International Journal of Computer Science \& Engineering Survey (IJCSES) Vol.5, No.2, April 2014

\section{ACKNOWLEDGEMENTS}

I thank my guide and everyone who give support in bringing out this paper.

\section{REFERENCES}

[1] Beeahara, A.H.Damasio and A.R.Damasio, (2000)“Emotion Decision making and orbit frontal cortex, 10(3): p 295-307.

[2] Ekman, P.Friesen "Facial Action Coding System",PaloAlto, CA,:Consulting Physiologists press, 1978.

[3] Ming-Husan Yang,David J.Kriegman,Narendra Ahuja ,"Detecting Faces in Images:A survey" IEEE Transaction on Pattern Analysis and Machine Intelligence",Vol.24,No.1,Jan 2002.

[4] Rajesh A Patil, Vineet Sabula, A.S.MandaI "Automatic Detection of Facial Feature Points in Image sequences”, 978-1-61284-861-7/11 IEEE 2011

[5] W. Kienzle, G. BakIr, M. Franz, and B. Scholkopf, "Face detection- efficient and rank deficient:' in Advances in Neural Information Processing Systems, vol. 17, pp. 673-t>80, 2005.

[6] P. Viola and M. Jones, "Robust real-time object detection:' in International Journal of Computer Vision, 2001.

[7] T. Kanade, J. Cohn, and Y. Tian, "Comprehensive database for facial expression analysis:' in Fourth IEEE International Conference on Automatic Face and Gesture Recognition, pp. 46 -53, 2000.

[8] Yu-Buhee and Sukhanlee " ETRI Journal, Volume 33,No.4,August 2011.

[9] Yow and Cipolla "Feature Based Human Face Detection" Image and Vision Computing vol15, No.9 pp 713-735,1997.

[10] A.Punitha,M.Kalaiselvigeetha "Texture based Emotion Recognition from Facial Expression using Support Vector Machine" International Journal of Computer Applications(0975-8887) Vol 80, No.5,October 2013.

[11] Sanjay Kr.singh,D.S.Chauhan,Mayank Vatsa,Richa Singh "A robust Skin Color Based Face Detection Algorithm" Tamkang Journal of Science and Engineering, Vol 6,No4,pp227-234(2003).

[12] Jiaming Li, Geoff Poulton, Ying Guo,Rong-Yu Qiao "Face Recognition Based on Multiple Region Features" Proc.VIIth Digital Image Computing:Techniques and Applications,Sunc, Talbot H,OurselinS. and Adriaansen T.(Eds), 10-12 Dec 2003,Sydney.

[13] Caifeng shan,Shaogang Gong,Peter W,Mcowan "Facial expression recognition based on Local Binary Patterns: A comprehensive Study" Image and Vision Computing 27(2009) 803-816.

[14] Rajesh A.Patil,Vineet Sahula and A.S.Mandal "Facial Expression Recognition in Image sequences using Active Shape Model and Support Vector Machine" 2011 UKSIM 5th European Symposium on Computer Modeling and Simulation.

[15] Yogesh Tayal,Pramod Pandey,D.B.V.Singh "Face Recognition using Eigenface" International Journal of Emerging Technologies in Computational and Applied Sciences (IJETCAS) 3 (1), Dec.12-Feb., 2013, pp. 50-55

[16] Jeemoni Kalita , Karen Das "Recognition of Facial Expression Using Eigenvector Based Distributed Features and Euclidean Distance Based Decision Making Technique" (IJACSA) International Journal of Advanced Computer Science and Applications, Vol.4, No.2, 2013.

[17] Sandeep K. Gupta, ShubhLakshmi Agrwal, Yogesh K. Meena, Neeta Nain "A Hybrid Method of Feature Extraction for Facial Expression Recognition" 2011 Seventh International Conference on Signal Image Technology \& Internet-Based Systems.

[18] Ziyang Zhang, Xiaomin Mu, Lei Gao " Recognizing Facial Expressions Based on Gabor Filter Selection" 2011 4th International Congress on Image and Signal Processing.

[19] Zhiguo Niu ,Prof. Xuehong Qiu "Facial Expression Recognition based on weighted principal component analysis andsupport vector machines" 2010 3rd International Conference on Advanced Computer Theory and Engineering (ICACTE).

[20] Marian Stewart Bartlett [Member, IEEE], Javier R. Movellan [Member, IEEE], and TerrenceJ. Sejnowski [Fellow, IEEE] " Face Recognition by Independent Component Analysis"IEEE Trans Neural Netw. 2002 ; 13(6): 1450-1464.

[21] Li-Fen Chen, Hong-Yuan Mark Liao, Ming-Tat Ko ,Ja-Chen Lin, Gwo-Jong Yu " A new LDA-based face recognition system which can solve the small sample size problem" Pattern Recognition 33 (2000)1713-1726. 
International Journal of Computer Science \& Engineering Survey (IJCSES) Vol.5, No.2, April 2014

[22] Teik-Toe TEOH Siu-Yeung CHO "Human Emotional States Modeling by HiddenMarkov Model" 2011 Seventh International Conference on Natural Computation.

[23] Er. Monika Verma Er. Pooja Rani Er. Harish Kundra A Hybrid Approach to Human Face Detection 2010 International Journal of Computer Applications(0975-8887)Vol 1-No.13.

[24] GwenLittlewort, Marian Stewart Bartlett "Dynamics of facial expression extracted automatically from video" Image and Vision Computing 24(2006) 615-625

[25] Chin-Shyurng Fahn,Ming-Hui Wu,Chang Yi Kao "Real-time Facial Expression Recognition in Image Sequences using an AdaBoost based Multiclassifier" Proceedings of 2009 APSIPA Annual Summit and Conference,Sopporo,Japan,october4-7,2009.

[26] Hiroshi Kobayashi and Fuimio Haro "Analysis of Neural Network Recognition characteristics at Basic Facial Expression" IEEE International Workshop on Robot and Human Communication 07803-2002-6/94, 1994 IEEE

[27] Chung-Lin Huang and Yu-Ming Huang " Facial Expression Recognition Using Model-Based Feature Extraction" Vol. 8, No. 3, September, pp. 278-290, 1997.

[28] BeatFaseIDIAP,Martigny"Head Pose invariant Facial Expression Recognition using Convolutional Neural Network" Fourth IEEE Internal conference on Multimodel interfaces 0-7695-1834-6/02 (C) 2002 IEEE.

[29] Khalid, Fatimah, Tengku Mod, Omar, Khiruddin "Face Expression Recognition with Relevance Vector Machine" ICME (Multi media \& Expo) IEEE International Conference Pg 193-196 24th Oct 2005.

[30] Aleksic P.S, Katsaggelos,"Automatic facial expression recognition using facial animation parameters and multi stream HMMS”, Vol1 Issue:1 Pg No: 3-11 March 2006 IEEE Signal Processing Society.

[31] Pritpal Dang, Harry Stephanou, Fredric Ham, Frank . L Lewis," Facial Expression Recognition using a Two Stage Neural Network", I-4244-1282--X107 (c) 2007 IEEE July 27-29 Althene - Greece.

[32] Govind U Kharat \& Sanjay V Didia," Emotion Recognition from Facial Expression Using Neural Network" 1-4244-1543-8/08 (C) 2008 IEEE.

[33] Kazmil S.B. Qurat - ul - Ain, Ishiag. M, Jaffar M.A," Texture analysis based facial expression recognition using a Bayesian classifiers", ICIET 2010 Pg No 1-6 9 Nov 2010.

[34] Jiequan Li, Oussalah M, "Automatic Face emotion recognition system" Cybernet Intelligent Systems (CIS) 2010 IEEE 9th International Conference Vol 1,Pg 1-6.

[35] Anissa Bouzalmat, Naouar Beghini, Arsalane Zarghili, Jamal Kharroubi," Face detection and Recognition using base propagation Neural Network and Fourier Gabor Filters" SIPIJ Vol 2, No.3 Sep 2011.

[36] Boughrara.H;Liming,chen;Ben Amar.C,Chtourou.M, " Face Recognition under varying Facial Expression based on Perceived Facial images and Local Feature matching "2012 International Conference on Information Technology and e Services, Pg 24-26 Mar 2012.

[37] Rahulmathavan Y;Phan R.D.-W;Chambers,J.A;Parish.D.J, 'Facial Expression Recognition in the Encrypted Domain Based on Local Fisher Discriminant Analysis"Affective Computing,IEEE Transcation on vol 4; issue 1,Jan-Mar 2013.

[38] DileepM.R,Aijit Danti,"Lines of Connectivity-Face Model for Recognition of the Human Facial Expressions"International Journal of Artificial Intelligence and Mechatronics Vol2,Issue2 ,ISSN 2320-5121. 